DR. HELEN COURTNEY-PRATT (Orcid ID : 0000-0002-6812-3360)

Article type : Original Article

\title{
'I WAS YELLED AT, INTIMIDATED AND TREATED UNFAIRLY’. NURSING STUDENTS' EXPERIENCES OF BEING BULLIED IN CLINICAL AND ACADEMIC SETTINGS
}

\author{
Authors \\ Dr Helen Courtney-Pratt (corresponding author) \\ Senior Research Fellow \\ $\mathrm{RN}, \mathrm{BN}, \mathrm{PhD}$ \\ Wicking Dementia Research and Education Centre \\ University of Tasmania \\ Private Bag 143, Hobart, TAS 7001 \\ Helen.courtneypratt@utas.edu.au \\ PH: +613 62264289 \\ Conjoint Senior Lecturer \\ School of Nursing and Midwifery \\ University of Newcastle \\ University Drive \\ Callaghan, NSW 2308 \\ Dr Jacqueline Pich \\ Lecturer \\ $\mathrm{BSc}, \mathrm{BN}, \mathrm{PhD}$ \\ University of Technology Sydney \\ 235 Jones St, Ultimo \\ Sydney, NSW 2007 \\ Jacqueline.pich@uts.edu.au \\ Ph: +61295145124 \\ School of Nursing and Midwifery \\ University of Newcastle \\ University Drive \\ Callaghan, NSW 2308
}

This article has been accepted for publication and undergone full peer review but has not been through the copyediting, typesetting, pagination and proofreading process, which may lead to differences between this version and the Version of Record. Please cite this article as doi: 10.1111/jocn. 13983

This article is protected by copyright. All rights reserved. 
Professor Tracy Levett-Jones

Professor of Nursing Education

RN, Phd, Med \& Work, BN, DipAppSc(nursing

University of Technology Sydney

235 Jones St, Ultimo

Sydney, NSW 2007

Tracy.levett-Jones@uts.edu.au

Ph: +61295145228

School of Nursing and Midwifery

University of Newcastle

University Drive

Callaghan, NSW 2308

Dr Annette Moxey

Manager Alzheimer's Australia

BA,Grad Dip H Soc Sci, PhD

AMA House, Level 1

42 Macquarie $\mathrm{St}$

Barton, ACT 2604

Annette.moxey@alzheimers.org.au

$\mathrm{Ph}:+62262788911$

The research was supported by an early research career grant from the University of Newcastle

We would like to acknowledge the contribution of all students who participated in the research.

\section{ABSTRACT}

\section{Aim}

To present findings from a study that explored nursing students' experiences of bullying in clinical and academic settings, the strategies used to negotiate bullying, and recommendations for empowering future students.

\section{Background}

Nursing students are identified as a group who are at particular risk of bullying. Numerous studies have examined students' experiences of bullying in clinical contexts by qualified nurses, however, there has been far less attention to the bullying that occurs in academic settings where the perpetrators are university staff

This article is protected by copyright. All rights reserved. 
and other students.

\section{Design}

The qualitative findings presented in this paper form one component of a mixedmethods, multi-site study that examined the nature and extent of bullying in one cohort of nursing students.

\section{Methods}

A convenience sample of 29 first, second and third year undergraduate nursing students from one semi-metropolitan Australian university was recruited for semistructured interviews in 2014. Interview data was analysed using NVivo.

\section{Findings}

Participants described multiple examples of bullying occurring in both clinical and academic settings. Perpetrators included clinicians, facilitators, academics and fellow students. Bullying ranged from incivility to physical attacks. The impact of the bullying was profound; it caused many of the participants to feel anxious and distressed, it undermined their confidence and perception of competence, and often led them to question their career choice.

Strategies described by participants to cope with or manage the bullying included avoidance, trying to 'just survive', and seeking support from trusted academic staff, family and friends. No episodes of bullying were formally reported.

\section{Conclusion}

Bullying remains a pervasive phenomenon occurring in both clinical and academic settings. Students are, in many respects, a vulnerable and disempowered population who often fear the consequences of making a formal complaint. Thus, reporting structures and support strategies need to be re-examined, and resilience training is imperative.

This article is protected by copyright. All rights reserved. 


\section{RELEVANCE TO CLINICAL PRACTICE}

Bullying remains a continuing concern in undergraduate nursing degrees. Efforts must be made in clinical and academic settings to heed the advice of undergraduates using broader strategies to address the issues.

\section{WHAT DOES THIS PAPER CONTRIBUTE TO THE WIDER GLOBAL CLINICAL COMMUNITY?}

1. Bullying occurs in academic and clinical settings with academic and clinical staff as well as students perpetuating this negative behaviour.

2. Undergraduates may be reticent to report on campus bullying due to fear of repercussions, and as such, academic staff may be unaware of the problems faced by students.

3. Previous research suggests schools of nursing have an inculcated and negative workplace culture that is in many ways consistent with those of healthcare settings. Strategies to build resilience across all areas of the undergraduate nursing degree may be effective in the longer term.

Keywords: bullying, violence, student, clinical placements, concerns preregistration education, qualitative descriptive and staff student relationships

\section{INTRODUCTION}

Nursing literature is replete with reports of bullying, a recognised phenomenon that, according to some commentators, has continued unabated for many decades (Jackson, Clare \& Mannix, 2002). Studies suggest that for many nurses, their

This article is protected by copyright. All rights reserved. 
everyday workplace is a hostile and harmful environment (Shields \& Wilkins 2006). One group that is particularly vulnerable to bullying is nursing students. Indeed, the metaphor of 'nurses eating their young' has become a frequently used and accepted part of the nursing vernacular (Curtis, Bowen \& Reid 2007). Although a wide body of international research indicates that bullying occurs in both academic and clinical settings, the latter context is of particular concern because of the potential impact on patient well-being and safety (Hutchinson, Vickers, Jackson \& Wilkes, 2006). Numerous studies have examined students' experiences of bullying in clinical contexts by qualified nurses (Magnavita \& Heponiemi 2011), however, there has been far less attention to the bullying that occurs in academic settings where the perpetrators are university staff or other students (Clarke et al. 2012).

This paper presents qualitative findings multi-site study that explored nursing students' experiences of bullying in clinical and academic contexts. These experiences, along with the strategies students used to negotiate the bullying, and recommendations for supporting students are discussed.

\section{BACKGROUND}

\section{Defining bullying}

Bartlett \& Bartlett (2011) refers to a continuum of counterproductive, disruptive and unacceptable behaviours ranging from incivility, through to harassment and bullying, and finally physical violence, which together constitute workplace bullying. The term bullying is sometimes used interchangeably with the words horizontal and vertical violence, and more recently incivility (Clarke and Kenaley 2011). Vertical violence refers to abusive behaviours occurring where there is a power imbalance between the perpetrator and the victim, for example registered nurse or academic to student nurse (Thomas and Burk 2009). Horizontal violence describes abusive behaviours perpetrated by those in a similar position, such as other nursing students. Both vertical and horizontal violence are acts of covert or 
overt aggression by an individual or a group towards another person, and can include physical, verbal or emotional abuse (Longo 2007). Workplace bullying includes behaviours such as excessive criticism, nonverbal innuendo (for example rolling of the eyes), withholding information, intimidation, exclusion, ridicule, making excessive demands, inequitable workload allocation, spreading rumours, scapegoating, and blocking opportunities for learning or promotion (Jackson et al. 2002). Incivility, which is described as a precursor to more serious events, differs somewhat from bullying, in that it encompasses actions that violate norms of behaviour, yet may result in unintended harm (Hunt and Marini 2012). For the purposes of this discussion the overarching term 'bullying' will be used to refer to any of the above behaviours.

\section{The historical background to bullying}

The phenomena of workplace bullying in nursing is underpinned by historical and cultural factors. Initially it was suggested that as an oppressed and predominantly female group subordinate to medicine, nurses exhibited bullying behaviours because they were unable to address issues with the real oppressor (Hutchinson et al, 2006). Croft and Cash (2012) suggest that the hierarchical nature of nursing, cultural subjugation, silencing of nursing voices and hegemonic understandings of how to address issues when they arise, have led to the perpetuation of power relationships and inaction in relation to the phenomena of bullying. Other reasons posited for negative workplace behaviours include burnout (Rowe and Sherlock 2005), workload acuity, and generational differences (Mitchell, et al. 2014). Fidelindo and Bernstein (2014) further advocate that individual personality styles and systemic factors, for example job pressure, cost containment, fear, authority structures, and constant change, all contribute to bullying.

This article is protected by copyright. All rights reserved. 


\section{Bullying and nursing students}

Bullying in nursing is said to be so pervasive that the vast majority of students will either witness or experience bullying while undertaking clinical placements (Budden et al, 2015). In clinical contexts bullying is perpetuated predominantly by hospital employed registered and enrolled nurses (Hutchinson et al, 2006), as well as university employed educators and facilitators who are charged with the responsibility to support students in practice (Budden et al, 2015). Although bullying is most prevalent in clinical contexts (Magnavita and Heponiemi 2011), emerging studies indicate that bullying also occurs in academic settings.

Students are a particularly vulnerable and disempowered group who fall victim to educators who engage in behaviours such as overly harsh marking of assessment items and humiliation in front of peers (Celik and Bayraktar 2004, Mott 2014). Students themselves can also be perpetrators of bullying, both face-to-face or via social media platforms (Clark, Werth et al. 2012).

Nursing students subjected to bullying have reported a range of negative consequences, which can be psychological, emotional, physical, professional and/or spiritual in nature (King-Jones, 2011, Thomas and Burk, 2009). These include attrition, anxiety, depression, reduced self-esteem, illness, poor academic attendance, and poor clinical performance. Bullying can have long lasting implications and influence students' professional roles and personal lives (Jackson et al, 2011). There have also been reports of self-harm and suicide secondary to severe bullying (Vessey, Demarco et al. 2010).

Studies have identified a strong link between workplace bullying and decreased patient safety. There is an increased risk of clinical errors, particularly when students are unwilling to ask questions and question in clinical settings known for a culture of bullying (Mitchell et al, 2014; Thomas and Burk, 2009). The risk of medication errors

This article is protected by copyright. All rights reserved. 
and medical errors (The Joint Commission 2008; Wright \& Khatri 2015) has been identified as an area of particular concern

A 'zero tolerence' policy is one approach for preventing workplace bullying. This encapsulates a stepped process to managing bullying and supporting both the perpetrator and victim. Although 'zero tolerance' is aligned with legislation recent critique has suggested that this approach has been 'impotent in stemming the tide [of workplace bullying]" (Hanley \& O’Rouke, 2015; Hurley et al 2016).

For students who may experience bullying in the workplace or tertiary setting there are often two similar but different processes to follow. Dependant on where the event takes place students may need to navigate processes within the university or within the university and workplace setting. The sense or belief that reporting would not change anything contributes to non-reporting, together with fear of losing one's position or job (Kvas \& Seljak, 2014). In addition to zero tolerance and reporting processes others have explored the use of resilience training (Delany et al, 2015; van der Riet, 2015); education and simulation (Pines et al, 2014; Ulrich et al, 2017). Yet such programs appear to remain at pilot level or as isolated initiatives and there is no requirement to embed them in undergraduate education despite the widespread impact of such experiences.

Given the pervasive, complex, and seemingly inevitable nature of bullying there is a need for further research in this area. In particular, an in-depth understanding, not only of students' experiences of being bullied, but also how they make sense of and negotiate such experiences, is needed. Importantly this paper explores the views of undergraduate nurses in relation to the interventions they believe would assist others in the future.

\section{METHODS}

The aim of this paper is to present findings from a study that explored nursing students' experiences of bullying in clinical and academic settings, the strategies

This article is protected by copyright. All rights reserved. 
they used to negotiate the bullying, and their recommendations for empowering future students.

\section{Study Design}

This study used a sequential mixed methods design with quantitative and qualitative data collected and analysed separately and sequentially (Creswell, 2003). The quantitative phase of the study sought to examine the extent of bullying in relation context and participants' demographic characteristics - these results will be published in a separate paper. The qualitative phase, as described in this paper, focused on an in-depth exploration of the experience of bullying. A qualitative descriptive approach was used as this is an appropriate method for exploring the nature and meaning of a particular phenomenon.

\section{Ethical considerations}

Ethical approval for the study was obtained from the university ethics committee (H2014-0270) prior to contacting potential participants. All participants provided written informed consent and data were de-identified to ensure anonymity in presentations or publications. As some participants were known to investigators, confidentiality was discussed at the beginning of the interview, participants were assured that they could discuss aspects of their experience they wished to, and they could end the interview at any stage. Names were replaced with codes. Any direct reference to individuals or workplaces was removed.

\section{Participant Recruitment}

Participants were recruited from one semi metropolitan Australian university with three sites between April and June 2014. A convenience sample of first, second and third year undergraduate nursing students from three campuses who had undertaken at least one clinical placement were eligible for inclusion.

This article is protected by copyright. All rights reserved. 


\section{Data Collection}

An announcement was posted on the electronic learning management system (Blackboards) and potential participants were sent an email with a link to the participant information statement and an invitation to complete an initial survey. At completion of the survey participants were invited to participate in a semi structured interview if they had experienced an episode of bullying. Interviews were scheduled after ensuring the participant did not identify any concerns related to the interview and interviewer allocation. Interviews were audio recorded and transcribed verbatim prior to analysis. The investigator who did not work directly with participants kept names and codes. As the topic held the potential to be distressing to participants counselling options were provided in the participant information sheet, and reiterated by the interviewer prior to commencement of the interview. Participants were offered the opportunity to review their interview transcript but each declined this offer.

\section{Data analysis}

Directed content analysis was employed to interpret the semi-structured interview data. Directed content analysis is a deductive process where systematic coding and categorisation of data is conducted using an agreed framework (Hsieh \& Shannon, 2005, p. 1278). In this study the open-ended interview questions provided the framework for the initial coding (Potter \& Levine-Donnerstein, 1999). The openended interview questions related to the experience of a bullying event; the strategies utilised to manage the event, a reflection on the role of the University in preparing students for such events, and exploring participant views on what may assist other students in the future.

The content analysis began by immersion in the text data and reading each of the transcripts. Using NVivo, all text that on first impression appeared to address the initial coding scheme was highlighted (Hsieh \& Shannon, 2005). The next step was to carefully examine the meaning of each of the highlighted sections. To enhance

This article is protected by copyright. All rights reserved. 
rigour an iterative process was used with three of the researchers (HCP, JP and TLJ) discussing the coding until consensus was reached (Koch, 2006). Reflexive processes also included an audit trail and memo writing to ensure the trustworthiness of the data (Sandelowski, 1986). The key findings from this process are presented below with descriptive evidence from direct participant quotes.

\section{FINDINGS}

\section{Participants}

Twenty nine nursing students, 27 female and two male, were recruited for the interviews. Five participants were enrolled in first year, 15 in second year, and nine in third year; they were aged 19 to 52 years with a mean age of 31 years.

Study findings are presented under the following categories that emerged during analysis:

- The experience of being bullied in clinical and academic settings

- Impact of the experience on students

- Strategies students used to 'make sense of' the bullying

- Recommendations from students on how to prepare for, and manage bullying.

\section{The experience of being bullied in clinical and academic settings}

Participants described bullying experiences that were both overt and covert, ranging from incivility through to physical assaults. The bullying occurred in clinical and academic settings. Perpetrators included nurses, facilitators, academic staff and other students. Quotes are coded by letter representing participants and a year of study (e.g A: Y2).

\section{Clinical settings}

Although the participants infrequently described physical violence, the impact on them when it did occur was significant:

This article is protected by copyright. All rights reserved. 
The nurse grabbed me by the arm, spun me out of the room and pushed me back down the corridor, telling me I was stupid... I went numb, it was the easiest way to deal with it...I didn't snap...it scares me that there's somebody out there like that...if this had happened in my first year I just would not have coped. (A: Y2)

The participants frequently described bullying experiences that were covert and insidious in nature. A sense of being excluded and treated as an unwelcome outsider was evident in many of the episodes recounted:

She [the registered nurse] wouldn't smile, she wouldn't talk to me... and after five weeks it was just really horrible. (C:Y3)

The senior staff did not talk to us, and when they did it wasn't in a nice manner (D:Y3)

A nurse just didn't want a bar of any students... I was put with her and she would just give you the ghastly jobs and talk down to you.(E:Y1)

A number of participants described clinical cultures where bullying was pervasive and recurring, and had a significant impact on staff and students.

The nurses were incredibly rude to each other ... and they were rude to us... ignoring us and being outright rude, saying 'we don't want students', and they would just disappear. I was like 'okay, well what do I do, where do I go?' It was really embarrassing and you just knew that you weren't wanted there. It made it really uncomfortable. (F:Y3)

It was a very unharmonious ward... every day there was conflict between them (the staff), so it wasn't just us ... it was unprofessional too (G:Y3)

Some of the participants experienced bullying from university employed clinical facilitators settings:

This article is protected by copyright. All rights reserved. 
I was yelled at and intimidated and flustered and treated unfairly. I've seen this person do it to other students while I was on previous placements but it never happened to me... I was treated differently and unfairly compared to the other students on placement. (H:Y3)

I was trying to ask questions and she would refer me to the course outline, but when other students would ask her she would answer... and give examples. There were two other students who noticed her behaviour too and they wanted to report it, but I said 'no, please don't because I don't want to get any further trouble...' (I:Y2)

In a number of instances the perpetrator of the bullying or the clinical site where it occurred had been previously identified as unsupportive or unwelcoming of students

She had a reputation of being rude and nasty and very unprofessional.(J:Y2)

I had heard rumours that it was not a particularly warm and welcoming ward.

(D:Y3)

\section{Academic settings}

The participants described multiple examples of bullying that occurred within the university environment perpetuated by both students and staff. Staff included those in tenured positions and those employed on a sessional basis, delivering tutorials or other learning activities.

A student was criticized and had her name documented by an academic staff member when she acknowledged that she was both studying and undertaking paid work.

She said 'When you come whinging and crying to me because you've failed then I want to remember your name, you cannot work and do uni'.(L:Y1)

This article is protected by copyright. All rights reserved. 
After a heated discussion in a tutorial class another student felt intimidated after being told (in front of other students):

'I want your name because you're obviously unhappy and psychologically disturbed" $(M: Y 2)$

This student then described how the tutor prevented her from leaving the classroom: I was leaving the room, I kind of got up to leave the room and she went in front of me to stop me leaving. (M:Y2)

Another student spoke of intimidation and perceived harassment when they described how an academic staff member:

... humiliated me and my friend in front of everyone (N:Y2),

Participants reported bullying being perpetuated by other students and that extended from having rumours spread about them, to being excluded and harassed on social media.

She [the other student] decided I was a terrible person and started trying to spread rumours about me and turn the whole year against me (Q:Y3)

I was previously with this group but then I noticed they were picking on other students and I ended up saying I can't deal with this and left the group. Then I kept getting information that she was saying things behind my back, saying that I wasn't going to make it- it was too hard for me... (U: Y1) Two girls would sit behind me and just bicker... in a way that you knew it was about you...then they started with Facebook and saying doubtful things about you (E:Y1)

Students from non-English speaking backgrounds described many examples of bullying and how they felt marginalised by such behaviours.

This article is protected by copyright. All rights reserved. 
In the second week [of a group assignment] they (other students) said 'we don't want to continue with these two girls just because of their background, because they're not English speaking as their first language'. (O:Y3)

Having English as second language puts me at a disadvantage, and my classmates brand me as something not really nice, or they can be very nasty to me...I got blamed for everything and I was left out of the information provided to others. (I:Y2)

\section{Impact of experiences on students}

Participants described how bullying resulted in feelings of anxiousness and distress, decreased confidence and the perception of competence. The experience also led to some students questioning their career choice:

It was very daunting to begin with ... it did deflate my confidence. (J:Y2)

You could have said 'boo' and I would have broken down at that point because two weeks of constantly being on edge and not knowing where this anger was going to come from or this rudeness... it just really kicked me down. (F:Y3)

I have a history of panic attacks but hadn't had had them since I finished school. I had them every day during placement and after placement.(K:Y3)

I didn't want to go back...I dreaded if she was on that shift...(T: Y3)

I am scared of handover now... I am so scared...can I do handover? (O:Y3)

One participant described the impact of bullying while enrolled in the nursing degree:

A lot of the students that I know dropped out, dropped out because it's too much, they got bullied, it's too hard, you know, the culture's too hostile... there's also no point in losing these brilliant people to something that's avoidable and to something

This article is protected by copyright. All rights reserved. 
that shouldn't be accepted and that the people who are perpetrating it should not be getting away with it. (C:Y3)

Other students described how bullying in the academic setting led to disengagement with learning and reluctance to attend classes. These on-campus episodes of bullying were rarely escalated or reported.

I didn't even come to the uni at that point because I wondered ... is it just me, am I making this worse than what it is - you know, maybe it's my personality that's clashing and don't want to be a whinger either. (R:Y2)

I ended up blocking my facebook, and I didn't come to tutes. I did a lot more at home where I felt more comfortable (E:Y1)

\section{Strategies students used to 'make sense of' and address bullying}

No students formally reported the incidences of bullying they experienced however, some sought advice and support from various trusted university staff.

I would speak to the tutor, all the tutors I have had are open to questions and talks (J:Y2)

The facilitator said she would speak to the unit manager (T:Y3)

Participants indicated a reluctance to report, felt it unlikely to lead to change, and also discussed times they had made a verbal complaint but were unsure of the outcome:

Am I going to cause a fuss? And am I going to rock the boat?, or am I just going to let it lie?. I don't know the answer to that but certainly that facilitator should have some sort of consequence to her behaviour, but she probably won't. and I know that she is best mates with another facilitator. You are in a no win situation and there is a bit of a power play. Going back to uni and giving them feedback is going to make it better or worse? Are you willing to risk it-I don't know. (M:Y2)

This article is protected by copyright. All rights reserved. 
There is not point telling anyone, because they all take her side (U: Y1)

I did report it to my facilitator, and my facilitator said she would take it further, but I felt like it wasn't dealt with. (P:Y3)

Students also utilise debrief with other students, sought assistance from formal counselling services, and turned to friends or families for advice and support.

I was seeing a counsellor, so I spoke to him a lot about it, and he came up with strategies, which helped a lot (E:Y1)

So it's great to talk to someone that's been through it. And the new grads out on placement are great because they are fresh out. They still remember uni and they have some good advice as well...(V:Y1)

...if you just get something off your chest and somebody says okay, you know, you're doing a good job or whatever, it's enough to just get you through those couple of days. It's kind of like you can do it, you can do it. Rather than feeling like you're completely on your own and outside of your depth. (F:Y3)

\section{Recommendations from students on how to prepare for, and manage bullying}

A recurring comment from participants was that the university had failed to prepare them with strategies to address bullying. Many felt that explicit and formal teaching sessions about bullying was required.

I think we need to be saying look this is a scenario that might happen to you, what are you going to do about it...because when it happens you are just so shocked. (D:Y3)

We need a lab session or tutorial on coping mechanisms and conflict resolution.(R:Y2)

The university need to let students know how to respond if someone does something; what your rights are; what you should say and do; who you can contact; as well as how you deal with the emotional fallout.(Q:Y3)

This article is protected by copyright. All rights reserved. 
There was also a general recognition that peer support and opportunities to discuss experiences with other students could be beneficial and help to build resilience:

Some of the girls had really really clever tips on how they resolved it [bullying]. (S:Y2)

If we just talked about it, really talked about it, I think I would have been a bit more prepared. D:Y3)

I just didn't take it personally' or didn't take it to heart' (P:Y3)

Whether you are first, second or third year, others should know they can go to the second and third years and go "hey I'm really struggling with this, could you...", because sometimes the student explains it better than a tutor can.. (A:Y2)

In addition a small number of respondents felt the university should have an immediate response person or system to ensure immediate support. One student poignantly described the current situation as she saw it:

So we send an email... and they (course coordinator) are going to answer in ten days. So what's the point? If something is going to happen it should happen straight away, but when they answer in ten days... it might be someone who is depressed and just want to suicide, they will do it in that time. (O:Y3)

We need a phone number or email for help and advice straight away, like you can call and say this has happened (D:Y30

\section{DISCUSSION}

The experience of being bullied described by the participants ranged from incivility through to being yelled at, intimidated, and treated unfairly. Although many of the events occurred in clinical settings, those that occurred in the tertiary settings perpetuated by academic staff or fellow students were equally distressing to 
participants. While it can be difficult to differentiate between experiences and label them as incivility or horizontal violence, this did not lessen the impact as reported by participants. In clinical settings, the bullying was at times reflective of a broader culture of aggression, disharmony and poor leadership. Our findings are consistent with those of Sinkknonen et al (2014) who found that university students reported bullying perpetrated by academic and clinical staff in similar measure. The students in our study describes a sense of powerlessness, exacerbated by the perception that a formal complaint may affect their marks or academic progress.

Research related to bullying in academic settings has not been subject to the level of research as that undertaken in clinical settings where there has been a long history of horizontal violence. Indeed, some commentators (for example Coleyshaw, 2010) suggest that universities are often reticent to investigate on campus examples of bullying and unwilling to accept that academic staff may be contributing to the bullying that they denounce. Yet academic settings, described as neoliberal in structure are hierarchical, power laden, individualistic and competitive and provide an ideal space for bullying to flourish (Zabrodska, 2011). It is suggested that schools of nursing have an inculcated negative workplace culture that is in many ways consistent with those of healthcare settings (Thompson \& Darbyshire, 2012). Thus, the finding of bullying perpetuated by nurse academics, should not be surprising given that they have prior exposure to nursing cultures where horizontal and vertical violence is often endemic (Hunt \& Marini; 2012). The participants in this study, who reasonably assumed that their nursing school would be a 'safe haven' where bullying would not be condoned, were often left disillusioned and distressed by the degree of rhetoric they encountered. Is it possible that academic staff are unaware of the impact of negative interactions with students and the feelings of unease they generate? As Mott (2014) urges, academics must be more open to understanding and addressing bullying, the perceptions of bullying and their own

This article is protected by copyright. All rights reserved. 
role. Our findings suggest that this understanding and action must reach outside only the clinical setting, and include academic and on line environments.

The bullying perpetuated by other students was a source of significant distress to students, particularly when it extended to social media and on line learning platforms. Cyberbullying is reported as an increasing phenomenon, particularly for female students (Faucher et al, 2014). This is of real concern in nursing where the majority of students are female. It would appear that the existence of cyber bullying policies alone, without a related training program and strong deterrents for those who perpetuate bullying, are unlikely to be effective. Faucher et al (2014) recommended anonymous reporting, stronger sanctions for perpetrators and university wide awareness and management, as possible solutions to address the issues. Yet our study indicates students are unlikely to report such events and instead will withdraw from the situations causing distress, either by not attending the university for lectures and tutorials, or by blocking social media. Such an approach indicates how students will take action to ensure their own psychological safety. It was not possible however for students to withdraw from the clinical setting, where completion of the placement is required as a component of the undergraduate degree.

A sense of safety and belonging are necessary precursors to engagement in learning and attainment of competence (Levett-Jones \& Lathlean 2009). However, for the participants in this study, the experience of being bullied caused them to question their right to be in the clinical milieu, with some even blaming themselves for the horizontal violence they encountered. This led to decreased confidence and disempowerment that had a negative impact on their capacity to learn in such an environment. The students were also aware that their learning opportunities were restricted in cases of incivility (for example individual nurses making it clear they were not happy to work with them). Behaviours that included humiliation or 
dangerous practices, led to students retreating to a safe mode where they would not expect or seek future learning for fear of retaliation or humiliation.

In order to address experiences of bullying students in this study offer some valuable insights. Debrief was identified by some students as an important step to better understand and manage bullying, however other were reluctant to 'rock the boat' by speaking up, and were unsure of consequences. Whilst a skilled facilitator should provide debrief that is inclusive and safe, encouraging active learning, in reality it is difficult to achieve and relies on individual skill and capacity to work with complex groups and situations. It has been recognised in the past that clinical facilitators are often poorly prepared for the role and have varied capacity to deliver learning opportunities (Salamonson, et al, 2014). Our findings support the need to ensure clinical facilitators are prepared and supported to achieve high levels of competency in the area of debrief, including addressing any violence that has been experienced.

Informal debrief with other students was seen as a strength of group placement, with some seeking support across year groups to establish expectations and coping mechanisms. This finding is important as it attests to the importance and potential benefits of peer support. It is a finding supported by O'Mara et al (2014) who found students turned to peers for support when faced with challenging clinical situations. We argue that greater focus in the tertiary setting to prepare students to provide such support would enhance the informal processes that occur. Future research could investigate the efficacy of such a program and enhance understanding of this important strategy.

At best the lack of action by academics in both clinical and university settings signals ignorance of the problem but at worst it is an abdication of responsibility. For example, if a student verbally reports a problem but does not feel able to complete a

This article is protected by copyright. All rights reserved. 
formal report then others can abdicate responsibility based on a lack of evidence or information on which to act. Together with a recognised reluctance of academics and universities to recognise and take action on bullying (Coleyshaw, 2010) we argue that such steps can amount to abandonment of nursing students. Within Australia, the pressure to source and retain sufficient numbers of clinical placements (Health Workforce Australia, 2014) may lead to a disinclination to censure clinical settings, even when bullying is a recurring occurrence. Some of the participants in the study recounted rumours being perpetuated about 'bad' placements and staff. When this occurred it exacerbated student apprehension but did not provide strategies to prepare for or negotiate bullying when it occurred.

Students in this study highlighted the need to prepare for the possible experiences of bullying. It is amongst several concerns students may have prior to their first clinical placement (Levett-Jones et al, 2015), and may be exacerbated if students have 'heard' about other students prior experiences. Despite calls for such preparation and resilience training to be embedded in curricula, it appears to be a neglected area. Delany et al (2015) provide findings to support resilience training in a study with physiotherapy students and claim it 'offers a powerful tool to build self efficacy and cognitive control'. Several authors have suggested pre placement preparation that include mindfulness (van der Riet, 2015) and resilience training using simulation (Pines et al 2014) that hold promise for enhancing preparation of students. An integrative review also supports interventions to enhance resilience of nursing students (Reyes et al 2015). Findings from other studies claim undergraduate nurses are able to draw on strategies to reframe and rebuild when faced with challenges (O'Mara et al, 2014), and that they often likely to draw support from peers (Reeve et al, 2013). Combined with the results of our study we would argue that any training, simulation or preparation should include a focus on peer support and assistance in challenging situations. The findings from our study demonstrate an overwhelming desire from students to experience broad preparation.

This article is protected by copyright. All rights reserved. 
The study's purposeful sample, while appropriate for qualitative designs, means that the findings cannot be assumed to be transferable to other contexts or cohorts. Additionally, the findings should be interpreted with a degree of caution as the participants were from only one university. Further research with other groups of learners would be valuable in taking this work forward.

\section{CONCLUSION}

The experience of bullying in nursing is longstanding and significant, particularly for students and novice nurses who often feel vulnerable and disempowered. A reluctance to formally report bullying, as indicated by the participants in this study, together with low recognition and inaction of the tertiary sector, who themselves may be perpetrators of such behaviours allows bullying to continue unabated. This study has identified that reliance on zero tolerance policies has done little to address the recurring incidence of bullying. Thus, further larger cohort research is needed to evaluate the impact of strategies designed to prepare students, to prevent and manage bullying. Enhancing resilience of nursing students holds promise for addressing the issue and should be embedded in nursing curricula, together with formal preparation of fellow students to provide peer support. It is evident therefore that universities must provide safe avenues for reporting of bullying and other negative workplace behaviours together with preparing students to address the issue using individual and collective strategies.

\section{RELEVANCE TO CLINICAL PRACTICE}

Bullying remains a continuing concern in undergraduate nursing degrees. Efforts must be made in clinical and academic settings to heed the advice of undergraduates, using broader strategies to address the issues.

This article is protected by copyright. All rights reserved. 


\section{REFERENCES}

Bartlett, J. E., \& Bartlett, M. E. (2011). Workplace bullying: An integrative literature review. Advances in Developing Human Resources, 13(1), 69-84.

Budden, L.M., Birks, M. Cant, R., Bagley, T. \& Park, T. (2015) Australian nursing students' experience of bullying and/or harrassment during clinical placement. Collegian

Celik, S.S. \& Bayraktar, N. (2004) A study of nursing student abuse in Turkey. Journal of Nursing Education, 43 (2), 330-336.

Clark, C. M., Werth, L. \& Ahten, S. (2012). Cyber-bullying and Incivility in the Online Learning Environment, Part 1: Addressing Faculty and Student Perceptions. Nurse Educator 37(4), 150-156.

Clarke, C. \&. Kenaley, B (2011). Faculty empowerment of students to foster civility in nursing education: a merging of two conceptual models. Nursing Outlook (59): 158165.Clarke, C. M., Kane, D. J., Rajacich, D. L., \& Lafreniere, K. D. (2012). Bullying in undergraduate clinical nursing education. Journal of Nursing Education, 51(5), 269-276.

Coleyshaw, L. (2010). The power of paradigms: A discussion of the absence of bullying research in the context of the university student experience. Research in Post-Compulsory Education, 15(4), 377-386.

Creswell, J. (2003). Research design: qualitative, quantitative, and mixed methods approaches (2nd ed.). Thousand Oaks, CA: Sage.

Croft, R. \& P. Cash (2012). Deconstructing contributing factors to bullying and lateral violence in nursing useing a postcolonial feminist lens. Contemporary Nurse 42(2), 226-242.

Curtis, J., Bowen, I.\& Reid. (2007)."You have no credibility: Nursing students' experiences of horizontal violence. Nurse Education in Practice 7, 156-163.

Delany, C., Miller, K. J., El-Ansary, D., Remedios, L., Hosseini, A., \& McLeod, S. (2015). Replacing stressful challenges with positive coping strategies: a resilience program for clinical placement learning. Advances in Health Sciences Education, 20(5), 13031324.

Faucher, C., Jackson, M., \& Cassidy, W. (2014). Cyberbullying among university students: Gendered experiences, impacts, and perspectives. Education Research International, 2014.

Fidelindo, A. \& I. Bernstein (2014). Civility and workplace bullying: resonance of Nightingale's persona and current best practices. Nursing Forum 49(2): 124-129.

Hanley, G. M., \& O'Rourke, A. (2015). The race without a finishing line: legislative means for confronting bullying in the Australian workplace. Asia Pacific Journal of Human Resources.

Health Workforce Australia (2014): Australia's Future Health Workforce- Nurses Overview.

Hunt, C. \& Z. A. Marini (2012). Incivility in the practice environment: A perspective from clinical nursing teachers. Nurse Education in Practice 12: 366-370.

Hurley, J., Hutchinson, M., Bradbury, J. \& Browne, G. (2016) Nexus between preventive policy inadequacies, workplace bullying, and mental health: Qualitative findings from the experiences of Australian public sector employees. Mental Health Nursing i25, 12-18.

Hutchinson, M., Vickers, M, Jackson, D. \& Wilkes, L. (2006). 'They stand you in a corner; you are not to speak': nurses tell of abusive indoctrination in work teams dominated by bullies. Contemporary Nurse, (21)2, 228-238

Hsieh, H-F \& Shannon, S (2005). Three Approaches to Qualitative Content Analysis. Qualitative Health Research, 15(9), 1277-1288

This article is protected by copyright. All rights reserved. 
Jackson, D., Hutchinson, M., Everett, B., Mannix,J. Peters,K.,weaver, R. \& Salamonson, Y. (2011) Struggling for legitimacy: nursing students'stories of organisational aggression, resilience and resistance. Nursing Inquiry, 18(2), 102-110

Jackson, D., Clare, J. \& Mannix, J. (2002). Who would want to be a nurse? Violence in the workplace-a factor in recruitment and retention. Journal of Nursing Management, 10, $13-20$

Koch, T. (2006). Establishing rigour in qualitative research: The decision trail. Journal of Advanced Nursing, 53(1), 91-100

King-Jones, M. (2011). Horizontal violence and the socialization of new nurses. Creative Nursing, 17(2), 80-86.

Kvas, A., \& Seljak, J. (2014). Unreported workplace violence in nursing. International Nursing Review, 61(3), 344-351.

Levett-Jones, T., \& Lathlean, J. (2009). The ascent to competence conceptual framework: an outcome of a study of belongingness. Journal of Clinical Nursing, 18(20), 2870-2879.

Levett-Jones, T., Pitt, V., Courtney-Pratt, H., Harbrow, G., \& Rossiter, R. (2015). What are the primary concerns of nursing students as they prepare for and contemplate their first clinical placement experience? Nurse education in practice, 15(4), 304-309.

Longo, J. (2007). Horizontal violence among nursing students. Archives of Psychiatric Nursing 21(3): 177-178.

Magnavita, N. \& Heponiemi,T. (2011). Workplace violence against nursing students and nurses: an Italian experience. Journal of Nursing Scholarship 43(2): 203-210.

Mitchell, A., Ahmed, A. \& Szabo (2014). Workplace violence among nurses, why are we still discussing this? Literature review. Journal of Nursing Education and Practice 4(4): 147-150.

Mott, J. (2014). Undergraduate nursing students experiences with faculty bullies. Nurse Educator 39(3): 143-148.

O'Mara, L., McDonald, J., Gillespie, M., Brown, H., \& Miles, L. (2014). Challenging clinical learning environments: Experiences of undergraduate nursing students. Nurse Education in Practice, 14(2), 208-213.

Pines, E. W., Rauschhuber, M. L., Cook, J. D., Norgan, G. H., Canchola, L., Richardson, C., \& Jones, M. E. (2014). Enhancing resilience, empowerment, and conflict management among baccalaureate students: outcomes of a pilot study. Nurse Educator, 39(2), 85-90.

Potter,W. J.,\&Levine-Donnerstein, D. (1999). Rethinking validity and reliability in content analysis. Journal of Applied Communication Research, 27, 258-284

Reeve, K. L., Shumaker, C. J., Yearwood, E. L., Crowell, N. A., \& Riley, J. B. (2013). Perceived stress and social support in undergraduate nursing students' educational experiences. Nurse Education Today, 33(4), 419-424.

Reyes, A. T., Andrusyszyn, M. A., Iwasiw, C., Forchuk, C., \& Babenko-Mould, Y. (2015). Resilience in nursing education: An integrative review. Journal of Nursing Education, 54(8), 438-444.

Rowe, M.M. \& Sherlock, H (2005). Stress and verbal abuse in nursing: do burned out nurses eat their young? Journal of Nursing Management 13, 242-248

Salamonson, Y., Everett, B., Halcomb, E., Hutchinson, M., Jackson, D., Mannix, J., ... \& Weaver, R. (2015). Unravelling the complexities of nursing students' feedback on the clinical learning environment: a mixed methods approach. Nurse Education Today, 35(1), 206-211.

Sandelowski, M. (1986). The problem of rigour in qualitative research. Advances in Nursing Science, 8(3), 27-37.

This article is protected by copyright. All rights reserved. 
Shields, M. \& Wilkins, K. (2006). Findings from the 2005 National Survey of the Work and Health of Nurses. Statistics Canada, Ottawa

Sinkkonen, H.M., Puhakka, H., \& Merilainen, M. (2014) Bullying at a university: students' experiences of bullying. Studies in Higher Education, 39(1), 153-165.

The Joint Commission. (2008) Behaviors that undermine a culture of safety. Sentinel event alert, issue 40. Retrieved from http://www.jointcommission.org/assets/1/18/SEA_40.pdf

Thomas, S. P. \& Burk, R. (2009). Junior nursing students' experiences of vertical violence during clinical rotations. Nurse Outlook 57(4): 226-231.

Thompson, D. \& Darbyshire, P. (2012). Is academic nursing being sabotaged by its own 'killer elite'? Journal of Advanced Nursing, 69(1), pages 1-3.

Ulrich, D. L., Gillespie, G. L., Boesch, M. C., Bateman, K. M., \& Grubb, P. L. (2017). Reflective Responses Following a Role-play Simulation of Nurse Bullying. Nursing Education Perspectives, 38(4), 203-205.

van der Riet, P., Rossiter, R., Kirby, D., Dluzewska, T., \& Harmon, C. (2015). Piloting a stress management and mindfulness program for undergraduate nursing students: Student feedback and lessons learned. Nurse Education Today, 35(1), 44-49.

Vessey, J. A., Demarco, R. \& diFazio R. . (2010).Bullying, harrassment, and horizontal violence in the nursing workforce: the state of the science. Annual Review of Nursing Research 28: 133-157.

Wright, W., \& Khatri, N. (2015). Bullying among nursing staff: Relationship with psychological/behavioral responses of nurses and medical errors. Health Care Management Review, 40(2), 139-147.

Zabrodska, K., Linnell, S., Laws, C., \& Davies, B. (2011). Bullying as intra-active process in neoliberal universities. Qualitative Inquiry, 17(8), 709-719.

This article is protected by copyright. All rights reserved. 